MATEC Web of Conferences 11,01008 (2014)

DOI: $10.1051 /$ matecconf / 20141101008

(C) Owned by the authors, published by EDP Sciences, 2014

\title{
Some durability aspects of hybrid alkaline cements
}

\author{
S. Donatello ${ }^{1}$, I. Garcia-Lodeiro ${ }^{1}$, A. Fernandez-Jimenez ${ }^{1}$ and A. Palomo ${ }^{1}$ \\ ${ }^{1}$ Eduardo Torroja Institute of construction sciences, Department of cement and materials recycling, Madrid, Spain
}

Abstract.

\begin{abstract}
Blended cements that contain a high content of fly ash and a low content of Portland cement typically suffer from low early strength development and long setting times. Recently, one method of overcoming these problems has been to use an alkali activator to enhance the reactivity of fly ash particles at early ages. Such cements can be grouped under the generic term "hybrid alkaline cements", where both cement clinker and fly ash, encouraged by the presence of alkalis, are expected to contribute to cementitious gel formation. The work presented here examines some of the durability aspects of high fly ash content hybrid alkaline cement. Specifically, the aspects investigated were: exposure at high temperatures (up to $1000^{\circ} \mathrm{C}$ ), resistance to immersion in aggressive solutions and susceptibility to the alkali aggregate reaction. All tests were repeated with a commercially available sulfate resistant Portland cement for comparison. When exposed to high temperatures, the hybrid alkaline cement showed strikingly different behaviour compared to the control Portland cement, showing fewer micro-cracks and maintaining residual compressive strengths at least equal to original strengths. Beyond $700^{\circ} \mathrm{C}$, the hybrid alkaline cement began to sinter, which resulted in shrinkage of around $5 \%$ and a $100 \%$ increase in residual compressive strengths. No such sintering event was noted in the control Portland cement, which showed a drastic loss in residual compressive strengths upon heating. In immersion tests, the hybrid alkaline cement possessed excellent resistance to sulfate and seawater attack, similar to the control sulfate resistant cement. Both cements were however severely degraded by immersion in $0.1 \mathrm{M} \mathrm{HCl}$ for 90 days. Both binders complied with the accelerated alkali-aggregate test but when this test was extended, the hybrid alkaline binder showed much greater dimensional stability. Possible reasons for the differences in durability behaviour in both cements are discussed, based on experimental evidence provided.
\end{abstract}

\section{Introduction}

Hybrid alkaline fly ash cements can be considered as a half way point between pozzolanic fly ash cements and alkali activated fly ash cements. To date there is very little information available in the literature regarding these binders $[1,2]$.

These cements need to be alkali activated to develop technologically viable early mechanical strengths. The alkaline activators used may be liquid or solid. The concentration and amount of activator used in each case depends largely on the $\mathrm{CaO}$ content in the cement blend and specific reactivity of the SCM.

Another important characteristic of these hybrid cements is that their hydration gives rise to a mix of reaction products, normally C-A-S-H and (N,C)-A-S-H gels. Studies are presently underway to determine the compatibility of these gels. Initial results in trials with synthetic gels indicate that they interact and tend to evolve toward a single composition [3-5].

Another important feature of these hybrid cements is their durability. Most of the papers on cement durability published to date address Portland or alkaliactivated slag or fly ash cements [6,7]. Consequently, little is known about hybrid alkali cement durability. The present study focuses on the behaviour of hybrid cement when exposed to high temperature, attack by aggressive chemical solutions $(0.1-\mathrm{N} \mathrm{HCl}$, sodium sulphates and seawater), and silica alkali reaction (ASR).

\section{Materials and Methods}

\subsection{Paste and mortar preparation}

Two different binders were used in this study. One was a reference Portland cement (MS) and the other was a hybrid alkaline coal fly ash cement (FAN-4). The fly ash used was of the class $\mathrm{F}$ type. The hybrid binder consisted of approximately $80 \%$ by dry mass fly ash and $20 \%$ by dry mass PC clinker. The mixture was activated by the incorporation of alkali into the mixture.

Prismatic paste specimens of $1 \times 1 \times 6 \mathrm{~cm}$ were prepared for the high temperature exposure tests so that expansion could be measured. Mortar cubes $(3 \mathrm{~cm})$ were prepared for the immersion tests in aggressive solutions. The mortars had a sand to binder ratio of $3: 1$. For the alkali aggregate reaction tests, mortar bars of

This is an Open Access article distributed under the terms of the Creative Commons Attribution License 2.0, which permits unrestricted use, distribution, and reproduction in any medium, provided the original work is properly cited. 
$2.5 \times 2.5 \times 28.5 \mathrm{~cm}$ and an aggregate to binder ratio of 2.25:1 as per ASTM C1260. All pastes and mortars were cured for at least 28 days in a humidity chamber controlled at $>95 \%$ relative humidity and $22+/-3^{\circ} \mathrm{C}$.

\subsection{High temperature exposure test}

Prismatic paste specimens $(1 \times 1 \times 6 \mathrm{~cm})$ were placed in an oven preheated to either; $200,400,600,800$ or $1000^{\circ} \mathrm{C}$ and left for 1 hour before being removed and either cooled in air or water. Samples were photographed before and after heat exposure. Selected pastes were also analysed by X-Ray diffraction (XRD) and scanning electron microscopy (SEM). In-situ shrinkage/expansion measurements were made using a dilatometer.

\subsection{Immersion in aggressive solutions}

A procedure based on ANSI ANS 16.1 was used where mortars cubes $(3 \times 3 \times 3 \mathrm{~cm})$ were immersed in a volume of solution $\left(\mathrm{cm}^{3}\right)$ equivalent to 10 times the total sample surface area $\left(\mathrm{cm}^{2}\right)$. The solutions used were ASTM seawater, $4.4 \% \mathrm{Na}_{2} \mathrm{SO}_{4}$ and $0.1 \mathrm{M} \mathrm{HCl}(\mathrm{pH} 1)$. Samples were immersed for up to 90 days and changes in weight and compressive strength measured. Solutions were replaced at regular intervals during the test.

\subsection{Alkali aggregate reaction (AAR)}

Mortar bars $(2.5 \times 2.5 \times 28.5 \mathrm{~cm})$ were prepared according to ASTM C1260 using non-reactive aggregates and either the MS or FAN-4 binder. As per the standard, mortars were immersed in a $1 \mathrm{M} \mathrm{NaOH}$ solution in a sealed container and placed in an oven set to $80^{\circ} \mathrm{C}$. Mortar bar lengths were measured daily during up to 90 days, exceeding the standard requirement of 16 days.

\section{Results and Discussion}

\subsection{High temperature exposure results}

The visual changes in paste samples following high temperature exposure are summarised in Fgure 1.

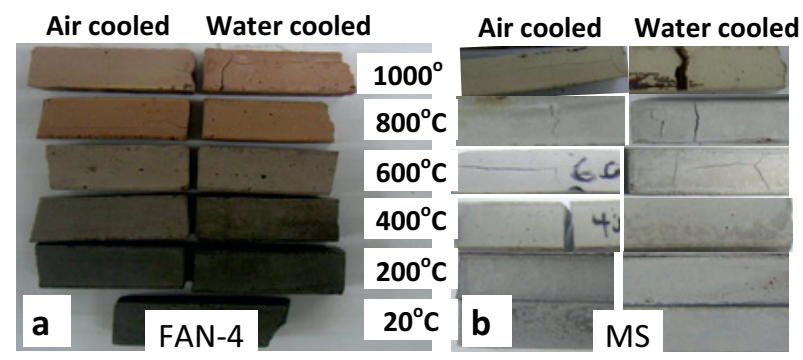

Fig. 1. Visual changes in a) hybrid alkaline cement and b) control PC pastes after temperature exposure.
It is clear that some reaction has taken place in the FAN-4 cement between 600 and $800^{\circ} \mathrm{C}$. Crack propagation was noted in $\mathrm{PC}$ pastes from $400^{\circ} \mathrm{C}$ onwards, most likely due to shrinkage caused by portlandite dehydration. A plot of changes in residual strength is included in Figure 2a along with in-situ dilatometry measurements in Figure 2b.

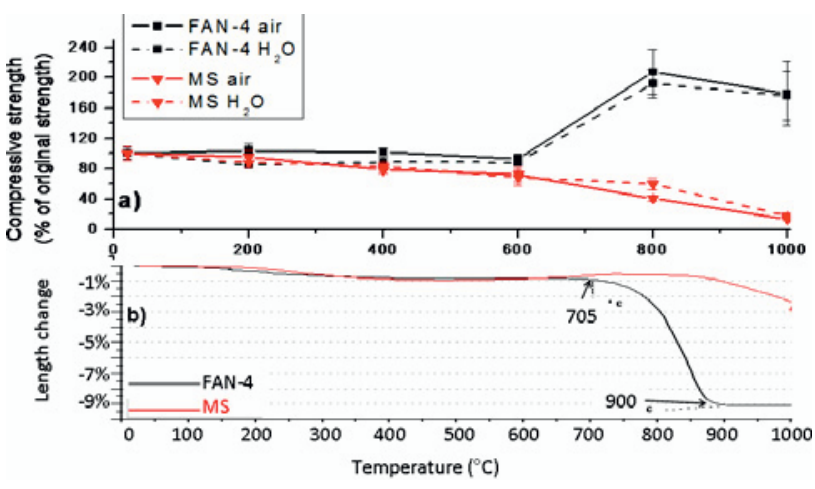

Fig. 2. Comparison of a) residual compressive strength evolution and b) shrinkage, in both MS and FAN4 cement as a function of increasing exposure temperature.

The reference PC showed steady and continual strength loss as temperatures increased. However, the hybrid cement almost doubled in original strength after exposure to 800 or $1000^{\circ} \mathrm{C}$. The strength increase was accompanied by a major shrinkage event as shown in Figure $2 \mathrm{~b}$ beginning at around $700^{\circ} \mathrm{C}$ and also coincides with the drastic colour change noted in Figure 1. These are all characteristic of sintering processes taking place in the hybrid cement which can be confirmed by comparing SEM images of the paste microstructure after exposure at 600 and $800^{\circ} \mathrm{C}$ (i.e. before and after the shrinkage event, see Figure 3).

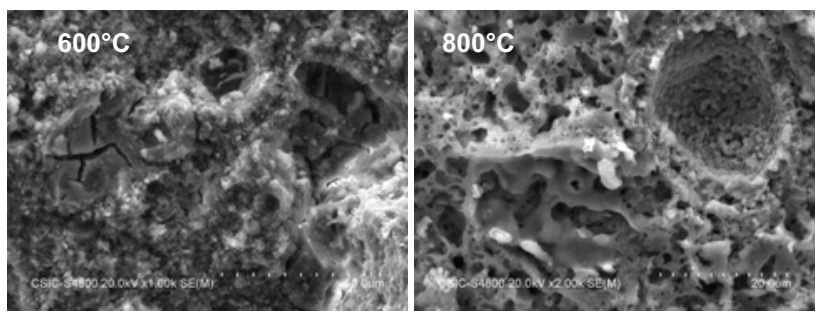

Fig. 3. Changes in FAN-4 paste microstructure after sintering event at around $700^{\circ} \mathrm{C}$.

The partial melting of the hybrid cement paste at low temperatures facilitated the formation of several new crystalline phases such as Fe-silicate, albite, gehlenite, anorthite, diopside and wollastonite (XRD data not included for brevity). Upon cooling of the partial melt, pastes showed greatly enhanced compressive strength.

\subsection{Aggressive solution immersion results}

Changes in relative compressive strengths after immersion in aggressive solutions for 7, 28, 56 and 90 days are illustrated in Figure 4. 


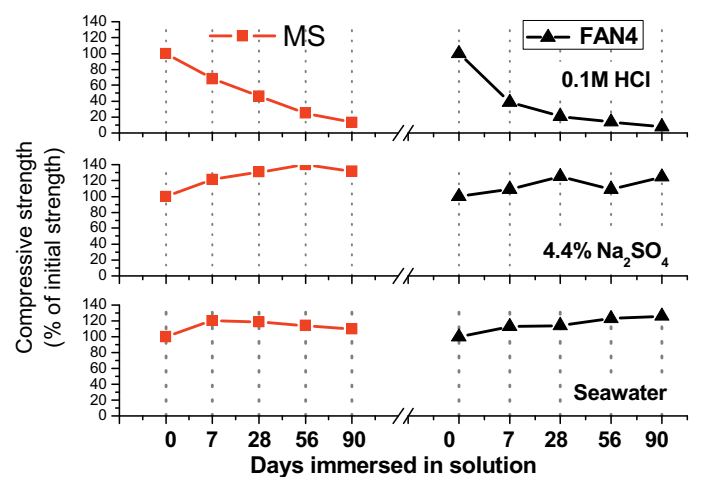

Fig. 4. Evolution of $\mathrm{PC}$ and hybrid cement mortar strengths following immersion in aggressive solutions.

The data in Figure 4 clearly shows that both mortars underwent drastic strength loss following acid immersion but that the rate of loss was initially slower in the control PC. In the sulphate and seawater solutions, both pastes actually showed net gains in strength with time.

Our reasoning for the more rapid loss of strength with acid immersed hybrid cements is linked to the nature of the $\mathrm{pH}$ buffering phases present. In the control PC, this is $\mathrm{Ca}(\mathrm{OH})_{2}$ (portlandite) and $\mathrm{CaCO}_{3}$. Both of these compounds are poorly soluble and so will not diffuse readily through the mortar pore network to the bulk solution where they would be rapidly neutralised. However, in the hybrid cement, very little $\mathrm{Ca}$ is present since on $20 \%$ of the binder consisted of PC clinker. Instead the alkali source is expected to be a combination of $\mathrm{NaOH}$ and $\mathrm{Na}_{2} \mathrm{CO}_{3}$. Both of these compounds are highly soluble and prone to interact with the acid via $\mathrm{pH}$ gradients in the pore solution.

When the $\mathrm{pH}$ of a pore solution drops, the cementitious gel begins to deteriorate and so too do the macro-structural properties of the mortar. The XRD data in Figure 5 confirms the deterioration of the gel phase to form an amorphous silica gel (results confirmed by SEM) type product in both systems. The main difference was that the process was somewhat quicker in the hybrid material than in the control PC.

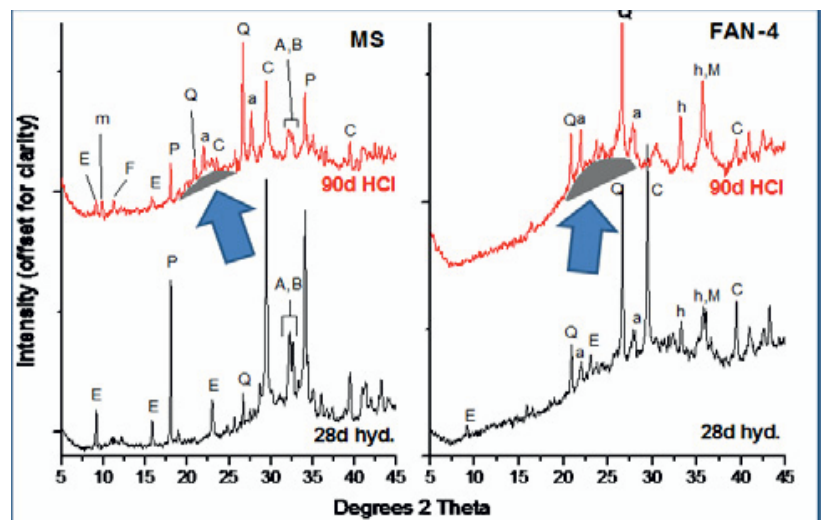

Fig. 5. Comparison of paste XRD before (bottom) and after (top) acid immersion for 90d. New amorphous silica gel phase highlighted by arrows.

\subsection{Alkali aggregate reaction results}

The results in Figure 6 reveal that both cements easily complied with the ASTM C1260 requirement of $<0.1 \%$ expansion after 16 days. However, when extending the test, a clear difference became apparent between the reference cement, which underwent significant and continual expansion, and the hybrid alkaline cement, which showed only very moderate further expansion.

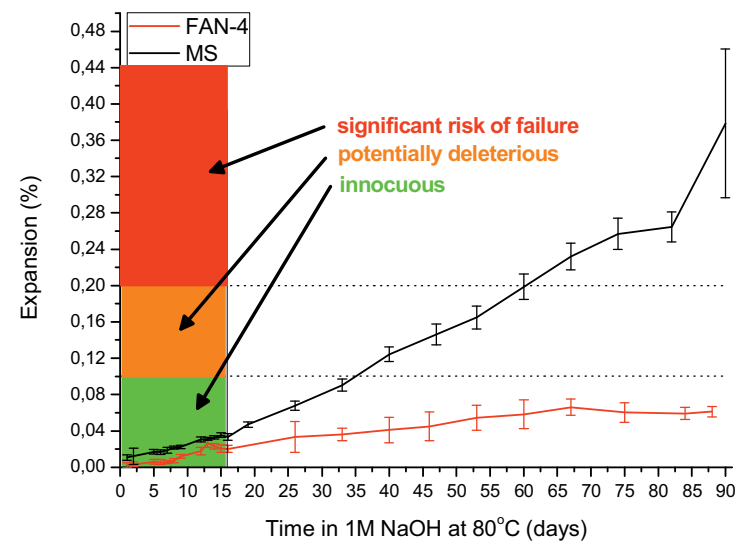

Fig. 6. Evolution of mortar bar expansion during the AAR test (according to ASTM C1260). Note that test period was extended up to $90 \mathrm{~d}$.

\section{Conclusions}

From the work presented it has been demonstrated that novel hybrid alkaline fly ash cements can demonstrate similar or even superior durability performance to that of a commercially available sulphate resistant cement.

\section{Acknowledgements}

This research project was funded under Spanish Ministry of Science and Innovation project BIA201017530.

\section{References}

1. A. Palomo, A. Fernandez-Jimenez, G. Kovalchuk, L.M. Ordonez, M.C. Naranjo. J Mater Sci 42, p.2858-66 (2007)

2. S. Donatello, A. Fernandez-Jimenez, A. Palomo. J Am Ceram Soc 96, p.900-06 (2013).

3. C.K. Yip, G.C. Lukey, J.S.J. van Deventer. Cem Concr Res 35, p.1688-97 (2005).

4. I. Garcia-Lodeiro, A. Fernandez-Jimenez, A. Palomo and D.E. Macphee. J Am Ceram Soc 93, p.1934-40 (2010).

5. I. Garcia-Lodeiro, A. Fernandez-Jimenez, A. Palomo, D.E. Macphee. Cem Concr Res 40, p.27-32 (2010).

6. T. Bakharev. Cem Concr Res, 35, p.658-70 (2005).

7. A. Fernandez-Jimenez, I. Garcia-Lodeiro, A. Palomo. J Mater Sci 42, p.3055-65 (2007).

8. I. Garcia-Lodeiro, A. Palomo, A. FernandezJimenez. Cem Concr Res 37, p.175-83 (2007). 